\title{
Ventral trunk somatosensory determinants of nursing behavior in Norway rats: 2 . Role of nipple and surrounding sensations
}

\author{
JUDITH M. STERN, LAURA DIX, CATHY BELLOMO, and CAROLINE THRAMANN \\ Rutgers-The State University, New Brunswick, New Jersey
}

\begin{abstract}
By manipulating the quality and quantity of pups, Stern and Johnson (1990) showed that ventral trunk stimulation from rooting and suckling pups elicits nursing behavior in lactating Norway rats by causing the dam to become immobile (low crouch) and to ventroflex, resulting in a high crouch. In the present study, the dams were manipulated, but the litters were not. Experimental treatments consisted of prepartum nipple removal, local anesthesia of all 12 nipples, with or without anesthesia of four abdominal sites without nipples (both of which blocked cutaneous sensitivity and milk ejection). Compared with that of controls, the maternal behavior of experimental dams was characterized by normal retrieval and licking of pups, increases in various active behaviors, and deficient nursing, that is, $<50 \%$ of them became immobile, briefly, and none displayed the high-crouch posture. Therefore, a full litter of capable pups cannot effectively stimulate nursing behavior in dams without nipples or in dams with their nipples and surrounding skin anesthetized.
\end{abstract}

Maternal behavior in Norway rats emerges from a complex cascade of physical interactions between the dam and her litter, thereby ensuring pup care necessary for the survival of the species (Stern, 1989; Stern \& Johnson, 1990, Figure 12). Before the onset of nursing, dams approach pups in response to distal stimuli from them (Stern, 1989; Stern \& Johnson, 1989), and then display a variety of oral activities directed at the pups and nest, including retrieval of stray pups, licking and rearranging pups, and nestbuilding; trigeminal stimulation that the dam receives from her snout contact with pups is necessary for her willingness to hover over the litter, from which position nursing can occur (Stern \& Johnson, 1989; Stern \& Kolunie, 1989). The ventral trunk (ventrum) somatosensory stimulation received from pups rooting for, attaching to, and suckling nipples elicits nursing behavior causing the dam to become immobile and to adopt the typical upright nursing posture, a high crouch characterized by a pronounced dorsal arch (or ventroflexion) and splayed, rigid leg support (Stern \& Johnson, 1990); these postural adjustments prevent the pups from being squashed while they suckle. Litters that are ineffective (e.g., due to chilling or anesthesia) cannot provoke their dams' cessation of motorically active behaviors and adoption of the crouching posture (Stern \& Johnson, 1990). By manipulating the ventrum of dams and then providing them with a sufficient number of effective pups, we show herein that cutaneous sen-

This research was supported by NIMH Grant MH-40459 (J.M.S) We thank Astra Pharmaceuticals for its generous gift of Sensorcaine and Linda York for her help with the collection of data. Correspondence should be addressed to J. M. Stern, Department of Psychology, Rutgers University, New Brunswick, NJ 08903. sations of the ventrum, particularly those from nipples, are critical in bringing about the rat dam's immobility and postural changes necessary for nursing to occur; a partial report of these results was presented recently (Stern, Dix, Pointek, \& Thramann, 1990).

\section{GENERAL METHODS}

\section{Animals and Housing}

Descendents of Long-Evans rats, Rattus norvegicus, purchased from Blue-Spruce Farms (Altamont, NY), were housed 3-4 per suspension cage, with Purina Rat Chow pellets and water available ad lib. Clock-controlled lights were on for $12 \mathrm{~h}$, starting at $0800 \mathrm{~h}$. Beginning when the rats were 70-120 days of age, vaginal smears were taken daily, and nulliparous females were mated overnight with a Long-Evans male on the night of proestrus; pregnancy was confirmed by the presence of sperm in the smear the next morning (= gestation Day 1). Subjects were rehoused individually at least 3 days prior to expected parturition in a clear, polypropylene pan cage $(42 \times 22 \times 20 \mathrm{~cm})$, with wood shavings for bedding and paper towel strips for nesting material. Within $24 \mathrm{~h}$ of parturition (= Day 0), litters were culled to 6 pups in Experiment 1 and to 8 pups in Experiments 2 and 3.

\section{Manipulations of Dams and Litters}

Each manipulation received prior approval from the Rutgers University Animal Care Committee. All experimental manipulations and testing were carried out between 0900 and $1700 \mathrm{~h}$. To increase incentive to display nursing behavior, litters were removed for $2 \mathrm{~h}$ (Experiment 1) or $4 \mathrm{~h}$ (Experiments 2 and 3) before testing. When separated from their dams, the litters were kept at nest temperature $\left(\sim 34^{\circ} \mathrm{C}\right)$, by being placed either under a $100-\mathrm{W}$ incandescent light (Experiment 1) or in a humid incubator (Experiments 2 and 3 ). The continuous observation period after dam-litter reunion was $30 \mathrm{~min}$. Litters were weighed before reunion and at one or more times after reunion. For surgery or subcutaneous injections, the subjects were anesthetized with a short-acting inhalant, methoxyflurane (Metofane, Pittman-Moore, Washington Crossing, NJ). 


\section{Behavioral Observations}

Behaviors were assessed with a minicomputer modified as an event recorder (S \& K Computer Products, Toronto, Canada). The most commonly observed behaviors included sniffing, licking, retrieval and mouthing of pups, self-grooming, nest-building or burrowing, exploratory behavior, hovering over pups (while motorically active), crouching (low, without, and high, with a pronounced dorsal arch continuously for $\geq 2 \mathrm{~min}$ ), and inactivity for $\geq 30 \mathrm{sec}$ while away from pups; see Stern and Johnson (1990) for further details on these behaviors. In addition, another behavior emerged in Experiments 2 and 3, prone, or lying flat over all or most pups while largely inactive, with little or no leg support; this behavior was keyed as "over pups" in Experiment 2, and was keyed separately in Experiment 3 . Behaviors that occurred rarely during the continuous observation period are not reported, including feeding, drinking, and the passive nursing posture (in which the dam lies on her side). If the dam did not retrieve all the pups within $5 \mathrm{~min}$, the test was interrupted while the observer placed the remaining pups in the nest.

\section{Data Analyses}

Fisher's exact probability test was used to assess group differences in the proportion of subjects in a given category. Latency, frequency, and duration of behaviors were analyzed using Student's $t$ test or analysis of variance, followed by a comparison of group means with the Newman-Keuls test. Statistical significance is accepted with a $p<.05$. Retrieval duration is the latency to pick up the last pup offered minus the latency to pick up the first pup. Contact time with pups is the sum of time over pups (including prone position) plus crouching (low and high). Analyses of latencies and retrieval duration included responders only. Group means \pm standard error are presented throughout.

\section{EXPERIMENT 1}

Removal of nipples (thelectomy) was first used by Wiesner and Sheard (1933) to determine whether absence of nursing and its physiological concomitant, lactation, interfered with the expression of maternal behavior. Their conclusion that maternal activities, including assumption of the "nursing posture," occurs normally without suckling and without regard to "drainage" of the mammary glands was supported by later reports from other workers (Moltz, Geller, \& Levin, 1967; Rosenblatt, 1967), including the present first author (Stern, 1977; Stern \& Levine, 1972). However, the criteria established by Stern and Johnson (1990) for nursing postures based on continuous observation, as well as the use of a sufficient dam-litter separation before the observation to ensure actual nursing by control dams, suggests that the methods used in previous reports of "nursing behavior" may not have been sensitive enough to distinguish between hovering over the litter while engaged in another activity, such as licking of the pups, and crouching while quiescent. Indeed, Wiesner and Sheard (1933) concluded that the nursing posture was "not very distinct," a conclusion with which we disagree (see Stern \& Johnson, 1990, Figure 1). In the first experiment, we reexamined the question of whether the absence of nipples alters the display of nursing behaviors.

\section{Method}

Surgery. Thelectomy (THEL) or sham surgery was performed either prior to mating ( $n=2$, THEL; $n=3$, SHAM) or 4-6 days postmating ( $n=7$, THEL; $n=6$, SHAM). The subjects were anesthetized for the duration of each surgical procedure (10-15 min). After the dam's ventrum was moistened with $95 \%$ alcohol, each nipple was grasped with a forceps, extended, and cut with scissors at the base. Sham surgery consisted of six small incisions, approximately the same size as the cut made by each nipple removal, on the midline of the ventrum, one between each pair of nipples. Suturing was not necessary, since bleeding was only slight and occurred rarely.

Maintenance of litters. In order to ensure a supply of healthy, well-fed pups for the subjects, 3 females were mated at the same time, 1 per group and 1 to serve as a donor of pups. While the litters of subjects were culled to 6 pups on the day of delivery, those of donors were adjusted to 12 pups. Daily switching of litters within a triplet occurred as follows: Pups previously with a THEL dam were given to a donor, the donor's 6 heaviest pups were given to a SHAM dam, and the pups previously with the SHAM dam were given to the THEL dam. In this way, a pup was deprived of nutrition for only 1 day out of 4 . At the time of switching, the pups were placed opposite the nest site, thereby providing dams with retrieval experience.

Behavioral testing. (1) Retrieval + nursing behavior test: On Day 4 or Day 5 postpartum, freshly suckled pups were removed from the donor, SHAM, and THEL dams $2 \mathrm{~h}$ before testing; the pups housed with the THEL dams were given to the donor dam, and the other pups were kept warm until the test. Although the dam-litter separation period was $4 \mathrm{~h}$ in most of our previous nursing behavior experiments (Stern \& Johnson, 1989, 1990), in this experiment, because of the nutritional stress imposed on the pups, that period was reduced to $2 \mathrm{~h}$. Unfamiliar pups were weighed and then placed opposite the dam's nest site at the beginning of the 30min continuous observation period and reweighed at $60 \mathrm{~min}$. (2) Dye test: The day after the previous test, a second nursing test was administered on 8 pairs of dams, also with unfamiliar pups and following a 2-h dam-litter separation. Just before reunion, a pipette was used to place a drop of food dye in the mouth of each pup. Behavior was not recorded, but at 30 and $60 \mathrm{~min}$ after reunion, the location of the dye on the dam's ventrum was noted. The purpose of this test was to see whether pups suck on a tuft of hair or on skin when nipples are absent.

\section{Results}

There were no differences between dams operated on premating and those operated on postmating, so these conditions were combined. The results of the dye test revealed that 1 of the THEL dams had a 13th nipple that was not removed at the time of surgery; therefore, the results of this female are excluded from the main analyses, leaving $n=8$ in this group and $n=9$ in the SHAM group.

Retrieval. All subjects retrieved all 6 pups, and the groups did not differ in their latencies to retrieve the $1 \mathrm{st}$ pup $(6.5 \pm 1.5 \mathrm{sec}$, THEL; $4.9 \pm 0.8 \mathrm{sec}$, SHAM) or the 6 th pup (38.5 $\pm 11.4 \mathrm{sec}$, THEL; $39.1 \pm 10.3 \mathrm{sec}$, SHAM).

Nursing behavior. After retrieval and grouping of the pups in the nest, all subjects hovered over the pups (Figure 1A), and dams in both groups spent an equivalent amount of time in the nest with the pups in various postures during the 30-min observation period (Figure 1B). However, fewer THEL than SHAM dams became immobile in the low-crouch posture $(9 / 9$ vs. $3 / 8, p<.02)$, and no THEL dams achieved the high-crouch posture (6/9 vs. $0 / 8, p<.01$ ) (Figure 1A); THEL dams spent twice as much time as did SHAM dams in hovering over pups without crouching $[t(15)=4.61, p<.001]$ (Figure 1B). Fur- 

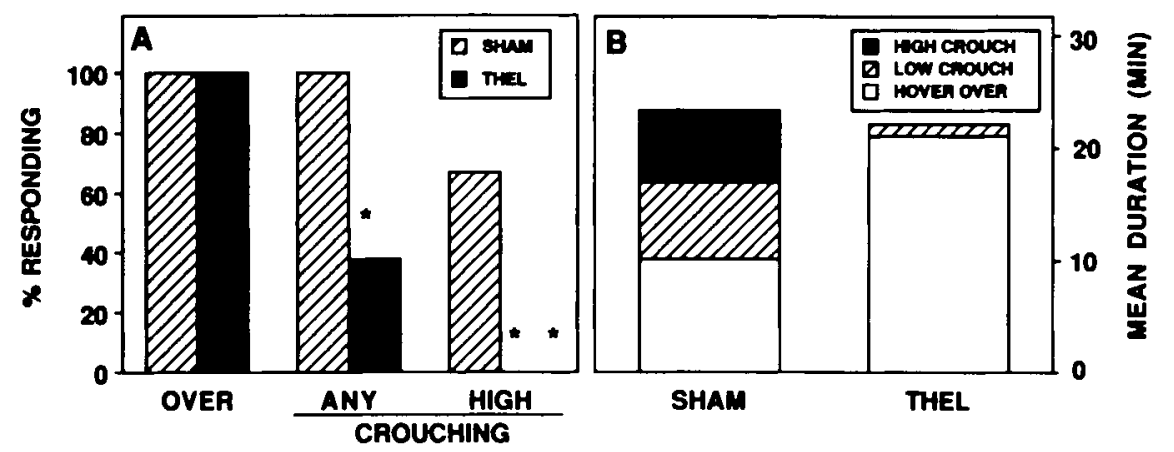

Figure 1. (A) Percentage of thelectomized (THEL, $n=8$ ) and sham-operated (SHAM, $n=9$ ) dams responding to pups during a 30-min period (following a 2-h separation) on Day 4 or Day 5 postpartum by hovering over them (over), becoming immobile in a low-crouch position (any) or in a high-crouch position (high). (B) Mean duration of the 30-min period spent in contact with pups in the three positions described in (A); the entire group is represented by these means. $* p<.02$. * $p<.01$.

thermore, of those subjects that crouched, latency to crouch was longer among THEL than among SHAM dams $(1,080 \pm 287 \mathrm{sec}$ vs. $643 \pm 87 \mathrm{sec})[t(10)=2.04$, $p=.069$ ], and THEL dams crouched only briefly, whereas the SHAM dams spent close to half of the observation period doing so $(179 \pm 18 \mathrm{sec}$ vs. $797 \pm 104 \mathrm{sec})[t(10)=$ $3.30, p<.01$ ].

The failure of THEL dams to adopt or remain in a nursing posture was correlated with about a threefold increase in self-grooming $[t(15)=3.50, p<.01]$, nest-building or burrowing $[t(15)=4.86, p<.001]$, and general activity $[t(15)=3.68, p<.01]$ (Figure 2 ). In addition, all subjects licked pups, THEL dams doing so for a somewhat longer time than controls $(831 \pm 86 \mathrm{sec}$ vs. $618 \pm$ $79 \mathrm{sec})[t(15)=1.83, p=.087]$.

At $60 \mathrm{~min}$, all but one litter with SHAM dams gained weight, the overall weight gain being $2.7 \pm 0.6 \mathrm{~g}$ (or $3.1 \pm$ $0.6 \mathrm{~g}$ for the eight litters with a gain). All litters with THEL dams lost weight, the average loss being $1.3 \pm 0.1 \mathrm{~g}$.

The THEL dam with one nipple displayed the lowcrouch posture for a longer time during the $30-\mathrm{min}$ observation period $(304 \mathrm{sec})$ than the 3 THEL dams with no

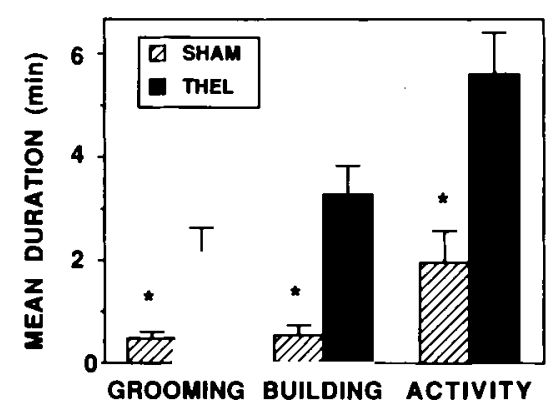

Figure 2. Mean duration (t standard error) of a 30-min period following reunion with pups of self-grooming, nest-building, or burrowing, and general activity, including walking and rearing; the entire group is represented by these means. " $p<.01$. nipples which crouched $(179 \pm 18 \mathrm{sec})$, and her litter gained $0.3 \mathrm{~g}$. Also, during the $30-\mathrm{min}$ observation period, her licking and building durations were shorter than those of the THEL dams with no nipples, and she did not self-groom.

Dye test. At 30 and $60 \mathrm{~min}$ postreunion, $8.5 \pm 0.4$ and $10.1 \pm 0.6$ nipples, respectively, of the SHAM dams had deposits of dye, most of them heavy; 1 dam also had dye in the perivaginal area. Very little dye was evident on the THEL dams with no nipples: all 8 had light dye deposits in the perivaginal region, which continued rostrally in 2 dams to the region where the most posterior nipples had been; 2 also had some dye on a thigh and 1 on a leg. The THEL dam with 1 nipple had a heavy deposit of dye only on this nipple.

\section{Discussion}

The results of this experiment are as follows:

1. Dams without nipples have normal retrieval behavior, in support of the findings of previous studies (Stern, 1977; Stern \& MacKinnon, 1976; Mayer et al., 1987).

2. Thelectomized dams spend as much time over pups in the nest as do dams with nipples, which undoubtedly led to the previous conclusions of normal nursing behavior by maternal rats without nipples (Moltz et al., 1967; Rosenblatt, 1967; Stern \& Levine, 1972; Wiesner \& Sheard, 1933). However, a careful delineation of the postures while over the pups, as well as other activities engaged in, revealed that the immobile low-crouch posture was displayed by only a portion of the thelectomized dams, and in these it occurred after a long latency and for a short time, while the high-crouch posture did not occur at all.

3. The failure of THEL dams to crouch, or to maintain the crouch posture, was accompanied by increases in other activities, such as pup-licking, self-grooming, nest-building or burrowing in the bedding, or general activity, including excursions from the nest. These results are consonant with our previous findings on intact dams 
that cared for pups that were not able to elicit their immobility and crouching posture because the pups could not suckle (Stern \& Johnson, 1990).

4. Only nipples are effective in stimulating suckling in pups, although the odors of the perivaginal area seem to provoke some mouthing movements, as judged by dye deposition from the mouths of pups in the absence of nipples on their dams. This is not surprising since rat pups require both olfactory (Hofer, 1976; Hofer, Shair, \& Singh, 1976; Singh \& Tobach, 1975) and tactile (Hofer, Fisher, \& Shair, 1981) inputs from nipples for attachment and suckling to occur.

We conclude that normal nursing behavior in lactating rats, which includes both prolonged quiescence and the high-arched crouching posture, is not dissociated from suckling, as has been maintained for close to 60 years.

\section{EXPERIMENT 2}

The failure of thelectomized dams to become immobile for long periods and to adopt the high-crouch posture may be due to: (1) a direct effect of the lack of the suckling stimulus on the dams' nervous systems or (2) behavioral responsiveness by dams to the continued activity of hungry pups rooting unsuccessfully for a nipple to attach to. In order to dissociate between these possibilities, nipple anesthesia was employed in this experiment. This procedure had previously been used with rabbit does, which typically nurse only once per day for several minutes; teat anesthesia increased the duration of nursing and was related to a second occurrence of nursing later that day (Findlay \& Tallal, 1971).

\section{Method}

Behavioral testing. (1) Retrieval + nursing behavior test: A maternal behavior test was carried out on Day 6, Day 7, or Day 8 postpartum. The dam-litter separation interval was $4 \mathrm{~h}$ before testing. One hour before testing, the subjects were anesthetized briefly with Metofane in order to carry out the injection procedure. The experimental subjects (NIP-B) were treated with $2.4 \mathrm{ml}$ of $0.375 \%$ bupivicaine (diluted with saline from a $0.5 \%$ solution of Sensorcaine with epinephrine, Astra Pharmaceuticals), a local anesthetic, by an injection of $0.2 \mathrm{ml}$ beneath each of the 12 nipples. For each nipple, the needle was inserted subcutaneously about $0.5 \mathrm{~cm}$ caudal to each nipple; the needle was rotated first to one side and then to the other, with $0.1 \mathrm{ml}$ being injected on each side. There were three control groups in which dams received, respectively: (1) 12 injections of saline $(0.2 \mathrm{ml})$ s.c., one beneath each nipple (NIP-S); (2) 12 injections of $0.375 \%$ bupivicaine $(0.2 \mathrm{ml})$ s.c., distributed on the back in a pattern resembling the pattern of nipples on the ventrum (BK-B); and (3) a single injection of $2.4 \mathrm{ml}$ of $0.375 \%$ bupivicaine i.p. (IP-B). There were 11 dams in each group. The latter two groups controlled for the possible systemic effects of a large dosage of local anesthetic (Kenyon, Cronin, \& Keeble, 1983). A 30-min continuous observation period was carried out after the weighed litter was placed opposite the dam's nest site; if retrieval was absent or incomplete by $5 \mathrm{~min}$, the pups were grouped in the nest by the observer. The litters were reweighed at $60 \mathrm{~min}$. Our criterion for effectiveness of the action of Sensorcaine in this experiment was a litter weight gain of no more than $0.5 \mathrm{~g}$ at $60 \mathrm{~min}$ after reunion. (2) Dye test: A separate group of 5 NIP-B dams was tested on Day 6 postpartum, as described in Experiment 2. One hour before reunion, the dams received 12 injections of $0.375 \%$ Sensorcaine, one beneath each nipple. Shortly before reunion, the urine of each pup was expressed, a drop of vegetable coloring was placed in its mouth, and the litter was weighed. Notes were made on the behavior of the dam and the litter for 30 min continuously; pups not retrieved by $5 \mathrm{~min}$ were placed in the nest by the observer. At $30 \mathrm{~min}$, the litter was reweighed, and the location of dye deposits on the dam was noted.

Cutaneous sensitivity. An independent assessment of cutaneous sensitivity following similar Sensorcaine treatment was carried out on a separate group of 9 lactating rats, Days 6-8 postpartum. Three hours after dam-litter separation and about $1 \mathrm{~h}$ before testing, each dam was anesthetized with Metofane and then given $120.2-\mathrm{ml}$ s.c. injections beneath each nipple, saline on one side and $0.375 \%$ Sensorcaine on the other, the sides being alternated from subject to subject. A diagram of the lactating rat's ventrum was used to record responses to pinches with a hemostat. For each pinch, the skin was gathered and then pressure applied by closing the hemostat. Responses were none (0), flinch (1), vocalization (2), or flinch + vocalization (3). Nipple sensitivity was tested carefully by pinching immediately rostral, caudal, medial, and lateral to each one. In addition, the sensitivity of sites more medial and lateral to the nipples and the nipple-less midventrum region was assessed.

\section{Results}

Retrieval. All dams sniffed the pups, $91.8 \%$ retrieved at least 1 pup, and $72.7 \%$ retrieved all 8 pups within 5 min. One dam did not retrieve in each of Groups BK-B and NIP-S, and 3 did not retrieve in each of Groups IP-B and NIP-B. There were no significant group differences in the number of pups retrieved, the proportion retrieving, or the latency to retrieve. The duration to retrieve all 8 pups was somewhat longer in Group IP-B than in the other groups $[F(3,28)=3.12, p<.05]$ (Table 1$)$, but this was due to a prolonged latency to retrieve the 8th pup by 2 dams; the latency to retrieve the 7 th pup did not differ by groups.

Nursing behavior. After the pups were retrieved and grouped in the nest by the dam, or gathered there by the experimenter, all dams hovered or lay prone over them, but although all control dams crouched in the 30-min period, only $5 / 11(45.4 \%)$ NIP-B dams did so $(p<.02)$ (Figure 3A). Furthermore, most control dams displayed the high-crouch posture $(26 / 33,78.8 \%)$, but none of the NIP-B dams did (Figure 3A). Therefore, NIP-B dams spent only about one third as much time crouching as did control dams $[F(3,40)=6.59, p<.001]$ (Figure 3B).

Dams in all groups spent a majority of the test period in the nest in contact with the pups, in various postures, although NIP-B dams spent somewhat less time doing so than did other dams (Figure 3B; Table 1). NIP-B dams displayed an increase in general activity compared with controls, especially those with their back skin anesthetized $[F(3,40)=3.27, p<.05]$. However, NIP-B dams did not display an increase in other active behaviors, and they licked pups significantly less than did controls, especially BK-B dams $[F(3,40)=3.22, p<.05]$ (Table 1 ). NIP-B dams' decreased total contact time with pups is also due in part to inactivity by 4 dams $(234 \pm 79 \mathrm{sec} ; 71 \pm$ $43 \mathrm{sec}$, averaged over the whole group); in contrast, only 1 dam in each of Groups BK-B and IP-B was inactive (for 
Table 1

Behavior of Lactating Rats, During 30 Minutes, Toward Pups on Day $7 \pm 1$ Postpartum as a Function of Presence or Absence of Nipple Anesthesia ( $n=11 /$ Group)

\begin{tabular}{|c|c|c|c|c|c|c|c|c|}
\hline \multirow[b]{3}{*}{ Behavior } & \multicolumn{8}{|c|}{ Group } \\
\hline & \multicolumn{2}{|c|}{ BK-B } & \multicolumn{2}{|c|}{ IP-B } & \multicolumn{2}{|c|}{ NIP-S } & \multicolumn{2}{|c|}{ NIP-B } \\
\hline & $M$ & $S E$ & $\boldsymbol{M}$ & $S E$ & $M$ & $S E$ & $M$ & $S E$ \\
\hline Retrieval (8 pups) & 39 & 8 & 84 & 24 & 36 & 3 & 41 & 5 \\
\hline Licking & 480 & $60^{2}$ & 351 & $72^{a b}$ & 423 & $57^{a b}$ & 211 & $70^{b}$ \\
\hline Grooming & 26 & 7 & 26 & 11 & 25 & 6 & 18 & 5 \\
\hline Building/burrowing & 44 & 25 & 79 & 30 & 98 & 36 & 62 & 32 \\
\hline Activity & 61 & $9^{n}$ & 140 & $26^{a b}$ & 102 & $21^{a b}$ & 162 & $35^{\mathrm{b}}$ \\
\hline Over pups & 659 & $80^{2}$ & 597 & $111^{2}$ & 477 & $76^{2}$ & 966 & $132^{b}$ \\
\hline Crouching & 890 & $71^{4}$ & 839 & $129^{a}$ & 914 & $80^{2}$ & 317 & $144^{b}$ \\
\hline Contact (total) & 1,549 & $67^{\star}$ & 1,435 & $63^{a b}$ & 1,391 & $49^{a b}$ & 1,283 & $74^{b}$ \\
\hline
\end{tabular}

Note-The control treatments were: BK-B, 120.2 -ml injections of $0.375 \%$ bupivicaine in the back, s.c.; IP-B, a single $2.4-\mathrm{ml}$ injection of $0.375 \%$ bupivicaine, i.p.; and NIP-S, 12 injections, one beneath each nipple, of $0.2 \mathrm{ml}$ physiological saline. The experimental treatment, NIP-B, consisted of $120.2-\mathrm{ml}$ injections of $0.375 \%$ bupivicaine, one beneath each nipple, s.c. Entries with different letters within a row are significantly different from each other $(p<.05)$.

64 and $334 \mathrm{sec}$, respectively), and none of the dams in Group NIP-S were inactive.

Litter weight gains. At $60 \mathrm{~min}$ after reunion, the groups differed significantly in the proportion with a gain and in the amount of gain $[F(3,40)=8.67, p<.001$; Table 2]. Litter gains were blocked for all or most of the $60 \mathrm{~min}$ in the NIP-B group, and among controls, NIP-S litters gained significantly more than did BK-B and IP-B litters.

Dye test. Two of the 5 NIP-B dams in this test retrieved all 8 pups, 1 retrieved only 1 pup, and 2 did not retrieve at all. In response to pups grouped in the nest, all dams licked pups repeatedly and lay prone over them once attachment to nipples occurred by most pups. Apparently because of the failure of the dams to accommodate the pups by adopting a crouching posture, the pups vocalized continually, often throughout the 30 -min period. Heavy dye deposits were found on $9.0 \pm 0.4$ nipples (range of 8-10); only 1 additional nipple had a light dye deposit in 2 dams, and no other deposits of dye were found on other parts of the dams' bodies.
Cutaneous sensitivity. On the side treated with bupivicaine $(0.375 \%)$, the nipples and the region medial to the nipples were insensitive to pinch (scores of 0 ), in contrast to median scores of 2 for these areas on the side treated with saline. Between 0.5 and $1.0 \mathrm{in}$. lateral to the nipple line, sensitivity similar to that on the control side was present on the anesthetized side, with increasing intensity of responsiveness the further lateral the pinches were applied. In the midventrum region, sensitivity also was considerably reduced compared with that on the control side, 6 of 9 females scoring 0 and the remaining 3 scoring $\leq 1$ vis-à-vis a median of 2 on the control side.

\section{Discussion}

These results show the following:

1. Nipple anesthesia blocked milk ejection up to $60 \mathrm{~min}$ postreunion (and $120 \mathrm{~min}$ after the local anesthetic was administered) in most dams; small gains in 3/11 litters indicate that, at the dosage and volume given, the treatment began to wear off after less than $2 \mathrm{~h}$ or that there was an inadequate spread of the anesthetic to all nipple afferents.
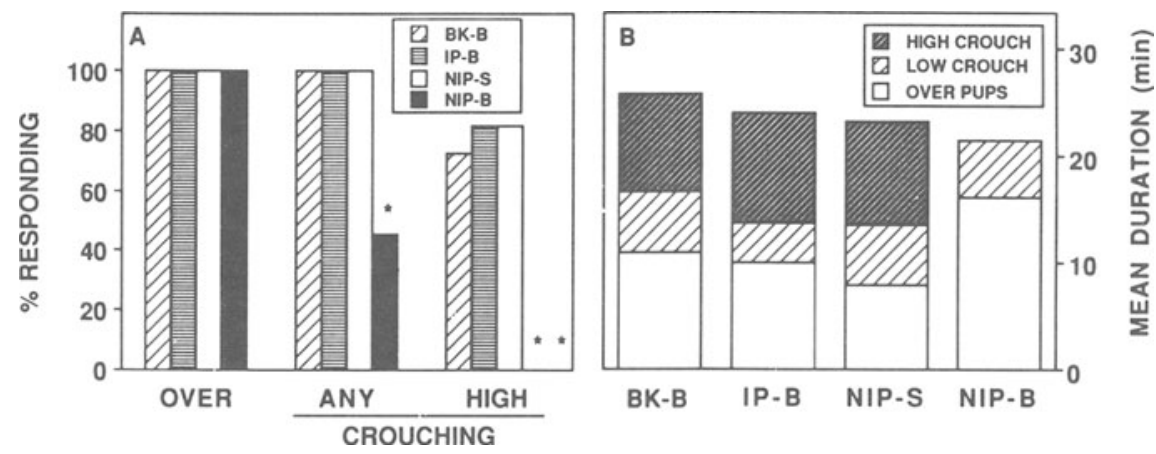

Figure 3. (A) Percentage of dams responding to pups during a 30-min period (following a 4h separation) on Day $7 \pm 1$ postpartum by hovering or lying prone over them (over), becoming immobile in a low-crouch position (any) or in a high-crouch position (high); $n=11$ /group. (B) Mean duration of the 30-min period spent in contact with pups in the three positions described in (A); the entire group is represented by these means. $\quad * p<.02$. * $p<.01$. 
Table 2

Relative Litter Weight Gains (in Grams) and Number of Litters With a Weight Gain $(\#+)$

\begin{tabular}{|c|c|c|c|c|c|c|}
\hline \multirow[b]{2}{*}{ Group } & \multirow[b]{2}{*}{$N$} & \multicolumn{2}{|c|}{ 0-30 MIN } & \multicolumn{3}{|c|}{ 0-60 MIN } \\
\hline & & $\mathbf{R W t} \mathbf{t}^{*}$ & $\#+$ & RWt & $\#+$ & $\# \geq 0.5 \mathrm{~g}$ \\
\hline
\end{tabular}

Experiment 2

$\begin{array}{lllll}\text { NIP-S } & 11 & 2.3 \pm 0.4^{\mathrm{a}} & 10^{\mathrm{a}} & 9^{\mathrm{a}} \\ \text { IP-B } & 11 & 1.3 \pm 0.4^{\mathrm{ab}} & 9^{\mathrm{a}} & 8^{\mathrm{a}} \\ \text { BK-B } & 11 & 0.7 \pm 0.3^{\mathrm{b}} & 7^{\mathrm{ab}} & 6^{\mathrm{a}} \\ \text { NIP-B } & 11 & 0.1 \pm 0.04^{\mathrm{c}} & 3^{\mathrm{b}} & 0^{\mathrm{b}}\end{array}$

\begin{tabular}{lcccccc}
\multicolumn{7}{c}{ Experiment 3} \\
CV & 10 & $2.6 \pm 0.8^{\mathrm{a}}$ & $8^{\mathrm{a}}$ & $3.9 \pm 0.9^{\mathrm{a}}$ & $8^{\mathrm{a}}$ & $7^{\mathrm{a}}$ \\
FV+ & 10 & $0^{\mathrm{b}}$ & $0^{\mathrm{b}}$ & $(0.3) \dagger^{\mathrm{b}}$ & $1^{\mathrm{b}}$ & $0^{\mathrm{b}}$ \\
FV- & 7 & $0^{\mathrm{b}}$ & $0^{\mathrm{b}}$ & $(0.2) \dagger^{\mathrm{b}}$ & $1^{\mathrm{b}}$ & $0^{\mathrm{b}}$ \\
\hline
\end{tabular}

Note-Within a column, letters that are different indicate a significant group difference $(p \leq .05) . \quad * \mathrm{RWt}$ (relative weight) $=$ gain of litter $\times 100$ /weight before reunion. $\quad+R W t$ of the single litter with a gain is given.

However, tests of cutaneous sensitivity on a separate group of lactating females suggest that at the time of testing the local anesthetic treatment was effective in desensitizing the nipples, the region medial to them, and, to a great extent, the nipple-less midventrum region as well.

2. Compared with control treatments, nipple anesthesia did not significantly interfere with retrieval or the licking of pups, similar to findings with thelectomized dams.

3. NIP-B dams spent considerable time in the nest with the pups, but only $45 \%$ of them displayed the low-crouch posture, none adopted the high-crouch posture, and the total time spent crouching was brief as compared with that of controls, findings also similar to those with thelectomized dams in Experiment 1. The results of the dye test confirmed our impression from the experiment proper that pups do manage to attach to the anesthetized nipples, despite the dam's lack of postural accommodation to them. Therefore, sensations from suckling stimuli seem to be necessary to provoke the high crouch and are also very important in inducing and maintaining crouching immobility.

4. Of the array of activities that normally precede the onset of nursing immobility, only general activity (walking and rearing) was increased significantly in NIP-B dams, and only in comparison with BK-B dams, while pup-licking duration was somewhat lower in the experimental dams. These results contrast with the more widespread increases in various activities by thelectomized dams. The most likely basis for these differences is that while NIP-B dams experienced the attachment of pups to their anesthetized nipples, THEL dams experienced continually active pups that were not able to attach to a nipple (or anything else), activity that provoked behavioral reactions in their dams comparable to those observed when active pups could not attach to a nipple consequent to anesthetic blockade of their infraorbital nerves or to acute suturing of their mouths (Stern \& Johnson, 1990). Furthermore, the quiescent suckling pups in Experiment 2 provided deep pressure stimulation to the whole ventrum, which was probably not affected by anesthesia of the skin, as well as tactile stimulation to parts of the ventrum not reached completely by the local anesthesia of the nipples, such as the region lateral to the nipples and possibly the nipple-less midventrum region. Another, not mutually exclusive, explanation for the differences between Experiments 1 and 2 is that some of the dams that received bupivicaine locally also sustained systemic effects of the drug. The similarity between Groups IP-B and NIP-B with respect to the number failing to retrieve (3), the durations of pup licking and general activity, and the smaller weight gains of the BK-B and IP-B litters compared with the NIP-S litters, all suggest possible deleterious systemic effects of the bupivicaine treatment in some dams.

\section{EXPERIMENT 3}

In terms of nursing behavior, the results of Experiment 2 were very similar to those of Experiment 1, even though pups had nipples to attach to. This suggests that it is the central effects of suckling stimuli rather than the inactivity of suckling pups which provokes dams to become immobile while standing over the pups and to adopt the high-crouch posture. However, a portion of the dams in both experiments did become immobile in the lowcrouch posture, albeit briefly. Also, systemic effects of the local anesthetic evident in some dams may have contributed to group differences in various behaviors.

In Experiment 3, we assessed whether cutaneous stimulation from the midventrum region, which is bare of nipples, contributes to the immobility of some dams with anesthetized nipples in response to suckling pups. In addition, we keyed separately a behavior seen in some dams with anesthetized nipples in Experiment 2 but considered as "hovering over" therein, that is, prone, lying flat over all or most of the pups. Finally, in an effort to further dissociate the local and systemic actions of the subcutaneously injected bupivicane, a large number of experimental dams were tested in order to break up the group statistically into those that retrieved all the pups and those that did not.

\section{Method}

The procedure was similar to that of Experiment 2, except for the following differences: Experimental subjects received $3.2 \mathrm{ml}$ of $0.28 \%$ bupivicaine (diluted with saline from $0.5 \%$ Sensorcaine), divided into 16 s.c. injections, $0.2 \mathrm{ml}$ beneath each of the 12 nipples and beneath four sites, two per side, between the pectoral and inguinal nipples (full ventrum, FV, $n=17$ ). The dilution was selected so that the total dosage of bupivicaine was the same as that used in Experiment 2 because preliminary observations revealed a much greater likelihood of nonspecific systemic effects (e.g., lethargy) with a higher total dosage of bupivicaine. The FV group was subsequently divided into dams that completed retrieval (FV+, $n=10)$ and those that did not (FV-, $n=7)$. There was only one control group, in which dams received 16 saline injections on their ventrums $(\mathrm{CV}, n=10)$. Litters were reweighed at 30 as well as at $60 \mathrm{~min}$ after the dam-litter reunion in order to more precisely correlate weight gains with those of the 30 -min behavioral observations.

Cutaneous sensitivity in response to eight injections of $0.28 \%$ Sensorcaine on one side of the ventrum and eight injections of sa- 
Table 3

Mean Durations and Standard Errors (in Seconds) of Behavior of Lactating Rats in 30 Minutes Toward Pups on Day $7 \pm 1$ Postpartum as a Function of Presence or Absence of Ventrum Anesthesia

\begin{tabular}{|c|c|c|c|c|c|c|c|c|}
\hline \multirow[b]{3}{*}{ Behavior } & \multicolumn{8}{|c|}{ Group $(N)$} \\
\hline & \multicolumn{2}{|c|}{ CV (10) } & \multicolumn{2}{|c|}{$\mathrm{FV}+(10)$} & \multicolumn{2}{|c|}{$F V-(7)$} & \multicolumn{2}{|c|}{ All FV (17) } \\
\hline & $M$ & $S E$ & $M$ & $S E$ & $M$ & $S E$ & $M$ & $S E$ \\
\hline Retrieval (8 pups) & 38 & 6 & 33 & 4 & - & & 33 & 4 \\
\hline Licking & 302 & $40^{a}$ & 597 & $65^{b}$ & 139 & $90^{2}$ & 408 & 76 \\
\hline Grooming & 58 & 22 & 50 & 17 & 25 & 16 & 40 & 12 \\
\hline Building/burrowing & 25 & 12 & 41 & 21 & 35 & 26 & 38 & 16 \\
\hline Activity & 137 & $29^{a}$ & 201 & $64^{2}$ & 424 & $96^{b}$ & 293 & 60 \\
\hline Over pups & 457 & $32^{*}$ & 1,294 & $114^{b}$ & 555 & $223^{2}$ & 990 & 142 \\
\hline Crouching & 1,100 & $68^{2}$ & 204 & $114^{b}$ & & & 120 & 70 \\
\hline Contact (total) & 1,567 & $51^{2}$ & 1,499 & $68^{a}$ & 555 & $223^{b}$ & $1, \overline{110}$ & 151 \\
\hline
\end{tabular}

Note-The control treatment was CV (control ventrum), $160.2-\mathrm{ml}$ injections of physiological saline, s.c., one beneath each of 12 nipples and 4 in the midventrum section; the experimental treatment, FV (full ventrum), consisted of injections of $0.28 \%$ bupivicaine, s.c., in the same sites. The experimental group was divided into dams which completed retrieval $(\mathrm{FV}+)$ and dams which did not retrieve at all or which retrieved $<8$ pups (FV-). In a comparison of Groups $\mathrm{CV}, \mathrm{FV}+$, and FV- by analysis of variance, entries with different letters within a row are significantly different from each other $(p<.05)$. In a comparison of Group CV and all FV subjects by unpaired $t$ tests, underlined entries under the "All FV" column are significantly different from CV $(p<.05)$.

line on the other side was assessed as described in Experiment 2 on a separate group of 9 lactating females, Days 6-8 postpartum.

\section{Results}

Retrieval. All CV dams and FV+ dams retrieved all 8 pups within 5 min, and these groups did not differ in retrieval latency or duration (Table 3). Among FVdams, 4 did not retrieve at all and 3 retrieved fewer than 8 pups $(5,3$, and 1 pup, respectively).

Nursing behavior. Following grouping of pups in the nest, all CV and FV+ dams and 4/7 of the FV- dams hovered or lay prone over their pups, all CV dams displayed both the low- and high-crouch postures, $40 \%$ of FV+ dams crouched, but only with the low-crouch posture [10/10 vs. $4 / 10, p<.02]$, and FV-dams did not crouch at all (Figure $4 A$ ). While only $20 \%$ of CV dams were ob- served to be prone, and only briefly, contributing $<7 \%$ to its group's total of "over pups," $80 \%$ of FV+ dams and $43 \%$ of FV-dams (or $75 \%$ of those that were over pups) were prone (CV vs. FV + , number prone, $p<.05$ ), contributing $35 \%$ and $72 \%$, respectively, to their groups' totals of "over pups." Of the dams that crouched, the latency to do so was much shorter among $C V$ than among FV+ dams $(483 \pm 42 \mathrm{sec}$ vs. $750 \pm 109 \mathrm{sec})[F(1,12)=$ $8.57, p<.02]$.

The groups differed significantly in duration of total contact $[F(2,24)=21.8, p<.0001]$, over pups $[F(2,24)$ $=14.49, p<.0001]$, crouching $[F(2,24)=47.7, p<$ $.0001]$, licking pups $[F(2,24)=7.77, \mathrm{p}<.01]$, and general activity $[F(2,24)=5.16, p<.02]$ (Table 3, Figures 4B, 5). FV + dams demonstrated a specific impairment in nursing behavior, including quiescence and the arched
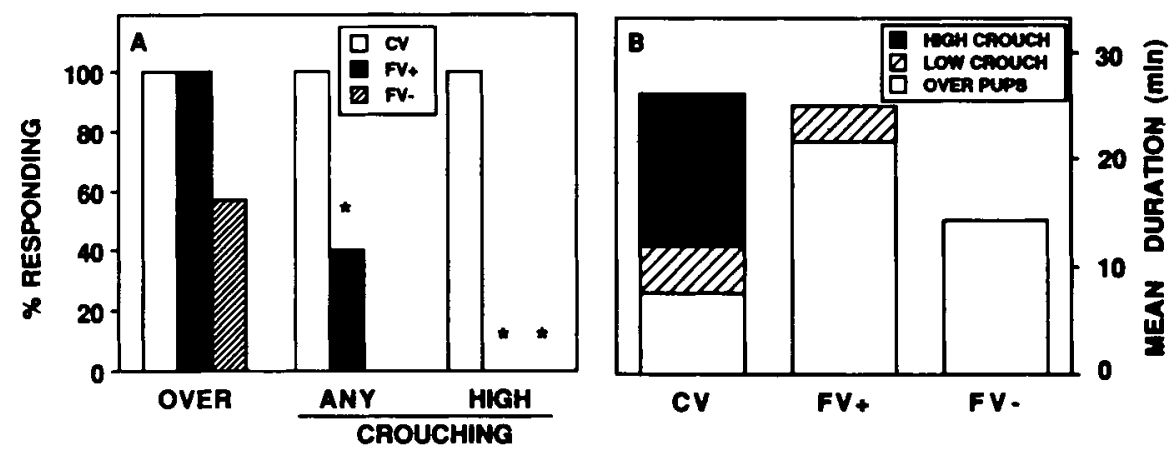

Figure 4. (A) Percentage of dams responding to pups during a 30-min period (following a 4h separation) on Day $7 \pm 1$ postpartum by hovering or lying prone over them (over), becoming immobile in a low-crouch position (any) or in a high-crouch position (high). Experimental dams, which received s.c. injections of local ancsthetic on the ventrum (12 nipple sites and 4 midventrum sites without nipples) (full ventrum, FV), were divided into those which retrieved all 8 pups (FV+, $n$ $=10$ ) and those which did not (FV-, $n=7$ ); controls received salime injactions (CV, $n=10$ ). (B) Mean duration of the 30-min period spent in contset with pups in the three positions described in (A); the entire group is represented by these means. ${ }_{p}<.02$. **p $<.01$. 


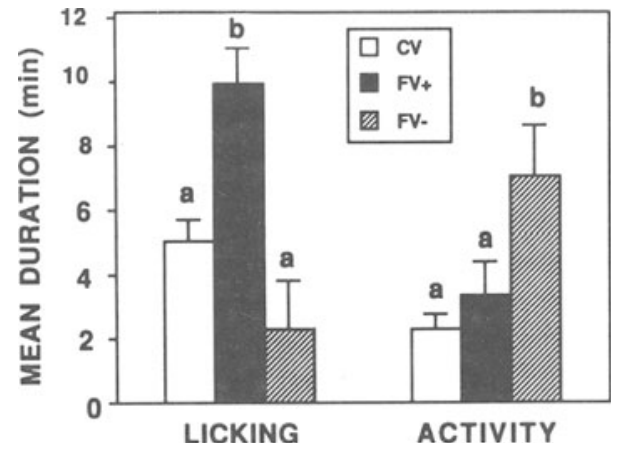

Figure 5. Mean duration (+ standard error), in a 30-min period following reunion with pups, of licking pups and general activity, including walking and rearing. The entire group is represented by these means. For each behavior, bars with a different letter are significantly different $(p \leq .05)$.

posture, resulting in greatly increased time over pups, in part while licking them, compared with CV dams. FVdams seemed to be affected systemically by the local Sensorcaine treatment, as indicated by the fact that $3 / 7$ were never over the gathered pups, by decreased pup licking, increased general activity away from the pups, and increased inactivity, as well as by absent or incomplete retrieval. While no $\mathrm{CV}$ dam and only $1 \mathrm{FV}+$ dam was inactive away from the pups (for $111 \mathrm{sec}$ ), $6 / 7 \mathrm{FV}-$ dams were inactive (for $202 \pm 52 \mathrm{sec}$, or $11 \%$ of the test time) (FV- vs. CV or FV+, number inactive, $p<.01$ ).

The FV group as a whole differs from the CV group in decreased duration of crouching $[t(25)=9.34, p<$ $.0001]$ and increased duration of total contact $[t(25)=$ $2.26, p<.05]$, over pups $[t(25)=2.83, p<.01]$, general activity $[t(25)=1.91, p<.07]$, and inactivity $(91 \pm 32$ vs. $0 \mathrm{sec})[t(25)=2.18, p<.05]$ (Table 3$)$.

Litter weight gains (Table 2). At $30 \mathrm{~min}$ after reunion, 8 of the $10 \mathrm{CV}$ litters had a weight gain whereas none of the 17 FV litters did. By 60 min after reunion, this difference persisted, although 1 litter in each FV subgroup did have a small weight gain.

Cutaneous sensitivity. The results with the 16-injection procedure (nipples + midventrum sites), using $0.28 \%$ bupivicaine, were very similar to those obtained with the 12 -injection procedure (nipples only), using $0.35 \%$ bupivicaine, in Experiment 2, with the following exception: in the midventrum region, there was no responsiveness to pinches on the anesthetized side (i.e., scores of 0 ) in any of the 9 females tested.

\section{Discussion}

The results of Experiment 3, consonant with those of the preceding experiments, suggest several conclusions:

1. Among FV dams with normal retrieval, nursing behavior was similar for both THEL and NIP-B dams in Experiments 1 and 2 in terms of percentage displaying the low crouch $(40 \%, 37.5 \%$, and $45.4 \%$, respectively), failure to adopt the high crouch at all, delayed onset of and brief time spent crouching, and substantial time spent over the pups, which was similar to that of control dams. Along with assessments of cutaneous sensitivity of the ventrum and blockade of litter weight gains, these results suggest that it is sensations from the nipples and surrounding skin that are critical in eliciting the dam's nursing behavior.

2. A comparison of thelectomized dams with nippleanesthetized (NIP-B) or full-ventrum anesthetized dams that displayed normal retrieval of pups (FV+) suggests an additional role for quiescent, suckling pups in contributing to a decrease in pup licking and in non-puporiented activities, such as exploration and rearing, nestbuilding, and self-grooming. A further comparison of the whole FV group with the FV+ and FV- subgroups provides an explanation for why these differences were not pronounced in Experiment 2; disrupted retrieval behavior, a likely indicant of a nonspecific systemic effect of the local anesthesia (cf. Kenyon et al., 1983), correlates with disruptions in other maternal behaviors. By removing systemically affected dams from the comparison with control dams in Experiment 3, the local effects of the anesthetic on maternal activities were more apparent.

3 . The prone position over the pups, displayed often by ventrum-anesthetized dams but not usually by control or thelectomized dams, indicates that continued leg support, as well as abduction of the legs (splaying) and ventroflexion that produce the high-crouching posture, are due to somatosensations from the ventrum. The quiescence over the pups in this posture may be the result of (1) a prepotent diurnal quiescence, (2) maternal tolerance of physical proximity to pups following the receipt of adequate trigeminal stimulation from snout contact with them (Stern \& Johnson, 1989), (3) the quiescence of the suckling pups, (4) residual cutaneous and deep pressure stimuli received from the suckling pups, or (5) a combination of these factors.

\section{GENERAL DISCUSSION}

The present findings of deficient nursing behavior in response to a sufficient number of effective pups in lactating Norway rats deprived chronically or acutely of nipple sensations provide a complement to findings on deficient nursing behavior that occurs when unmanipulated dams are reunited with litters that are incapable of suckling or insufficient in number (Stern \& Johnson, 1990). Similarly, in the absence of normal nursing behavior, whether the cause of deficient stimulation of the ventrum is exogenous (Stern \& Johnson, 1990) or endogenous (present results), there is an increase in activities, both pup-oriented (e.g., licking) and non-pup-oriented (e.g., self-grooming), that usually precede or follow a nursing bout. Together, these results indicate that suckling by pups causes the rat dam (1) to become immobile, and (2) to alter her posture reflexively. Behavioral changes in mothers in response to appropriate tactile stimulation from suckling young also have been noted for rabbits (Fuchs \& Wagner, 1963), guinea pigs (Harper, 1976), domestic 
swine (Fraser, 1976), ewes (Vince, 1987), ponies (Keiper, 1985), whales (Slijper, 1979, pp. 381-382), and bushbabies (Doyle, Anderson, \& Bearder, 1969). In most of these species, inappropriate tactile stimuli from offspring were observed to result in such maternal activities as circling by ewes or pup licking by rat dams, which enable the sequence to begin again.

It is apparent that ample distal stimuli from young (i.e., seeing, hearing, and smelling them), even when received by an experienced mother, are not sufficient for normal nursing behavior to occur and that offspring provoke nursing behavior by their own activities which provide tactile stimulation to the ventrum. For example, dams in the present study did not respond to the vocalizations of their pups by adopting the crouching posture when the appropriate ventral stimulation was absent or inadequate. It is not likely that the presence of pup vocalizations prevents normal nursing behavior, because pup vocalizations are common at the beginning of the nursing bout until all pups have achieved nipple attachment. Furthermore, it is not likely that the absence of pup vocalizations per se enhances the likelihood of crouching over pups gathered in the nest, because silent (dead or anesthetized) pups that are incapable of rooting or suckling do not stimulate their dams to crouch (Stern \& Johnson, 1990).

Effective ventrum stimulation from pups includes tactile and pressure stimuli from their snouts while rooting, suckling per se, and treading with their paws while suckling. Recording from nipple afferents show that there is neuronal activation in response to stimulation from surrounding skin as well as from nipples (Findlay, 1966). Apparently, these stimuli elicit the upright nursing posture by activating well-known reflexes, that is, stretch, withdrawal, and bilateral leg extension. In response to appropriate but insufficient ventrum stimulation, whether from an exogenous (e.g., small litter) or an endogenous (no nipples or anesthetized nipples) cause, crouching immobility either does not occur or it occurs after a long delay and does not last long (Stern \& Johnson, 1990; present results).

Suckling, well-known to inhibit tubero-infundibular dopamine (DA), thereby enhancing prolactin secretion (Ben-Jonathan, 1985), also may inhibit nigrostriatal dopamine, thereby resulting in dams' becoming quiescent and sensitive to ventrum somatosensory stimulation (Stern \& Taylor, 1991; Stern, 1991). Administration of haloperidol, a DA receptor antagonist, results in a dosagedependent inhibition of retrieval, licking, and nestbuilding (Giordano, Johnson, \& Rosenblatt, 1990; Stern \& Taylor, 1989, 1991) and facilitation of nursing behavior in response to suckling pups (Stern \& Taylor, 1989, 1991). Similarly, DA antagonism with haloperidol inhibits the motorically active components of feminine sexual behavior in rats, that is, darting and hopping (proceptivity), whereas it enhances the likelihood and intensity of the immobile lordosis posture (receptivity) in response to flank and perineal somatosensory stimulation (Hansen, Stanfield, \& Everitt, 1981). A catalepsy-inducing dosage of haloperidol ( $5 \mathrm{mg} / \mathrm{kg}$ ) administered to maternally naive virgin female and male rats (not treated with hormones known to induce maternal behavior) results in the rapid elicitation of the upright nursing posture in response to ventrum stimulation from the rooting of hungry pups (Stern, 1991). Because these rats had undeveloped nipples (virgin females) or no nipples (males), this finding indicates that sufficient DA antagonism not only induces motoric inactivity but also enhances sensitivity to appropriate somatosensory inputs, such that suckling per se is not required to elicit the nursing posture.

Analogies between maternal behavior and feminine sexual behavior in rats are heuristically profitable (Stern, 1990 , p. 192). The upright crouching posture, like lordosis (see Pfaff \& Modianos, 1985), is bilaterally symmetrical, involves all or most of the spinal cord, and consists of a concatenation of reflexes dependent upon cutaneous pressure on a wide area of the trunk. The nursing posture differs from that of lordosis in terms of the site of effective stimulation (ventral trunk vs. flank and perineum), and therefore in the direction of the spinal arch (ventroflexion vs. dorsoflexion), in the duration of effective stimulation, and therefore in how long the posture is held ( $\geq 20 \mathrm{~min} v \mathrm{vs} .<1 \mathrm{sec}$ ), and in its independence from direct ovarian hormone control (Stern, 1991). The ventrolateral columns of the spinal cord contain the fibers necessary and sufficient for lordosis (Kow, Montgomery, \& Pfaff, 1977), and preliminary results indicate that lateral column lesions eliminate the upright crouching posture (and milk ejection) but not other aspects of maternal behavior (J. M. Stern, D. P. Crockett, \& M. D. Egger, work in progress). Our working hypothesis is that the fibers necessary for normal nursing behavior are not in the ventrolateral columns (which is the case for lordosis), but rather in the dorsolateral columns, overlapping those necessary for the milk-ejection reflex (Fukuoka, Negoro, Honda, Higuchi, \& Nishida, 1984).

\section{REFERENCES}

Ben-Jonathan, N. (1985). Dopamine: A prolactin-inhibiting hormone. Endocrine Reviews, 6, 564-589.

Doyle, G. A., Anderson, A., Benrder, S. K. (1969). Maternal behavior in the lesser bushbaby (Galago senegalensis moholi) under semi-natural conditions. Folia Primatologica, 11, 215-238.

Findlay, A. L. R. (1966). Sensory discharges from lactating mammary glands. Nature (London), 211, 1183-1184.

Findlay, A. L. R., T TallaL, P. A. (1971). Effect of reduced suckling stimulation on the duration of nursing in the rabbit. Joumal of Comparative \& Physiological Psychology, 76, 236-241.

Fraser, D. (1976). The nursing posture of domestic sows and related behaviour. Behaviour, 57, 51-63.

Fuchs, A. R., WAGNER, G. (1963). Qualitative aspects of release of oxytocin by suckling in unanesthetized rabbits. Acta Endocrinologica, 44, 581-592.

Fukuoka, T., Negoro, H., Honda, K., Higuchi, T., Nishida, E. (1984). Spinal pathway of the milk-ejection reflex. Biology of Reproduction, 30, 74-81.

Giordano, A. L., Johnson, A. E., Rosenblatt, J. S. (1990). Haloperidol-induced disruption of retrieval behavior and reversal with apomorphine in lactating rats. Physiology \& Behavior, 48, 211-214. Hansen, S., Stanfield, E. J., \& Everitt, B. J. (1981). The effects 
of lesions of lateral tegmental noradrenergic neurons on components of sexual behaviour and pseudopregnancy in female rats. Neuroscience, 6, 1105-1117.

HARPER, L. V. (1976). Behavior. In J. E. Wagner, \& P. J. Manning (Eds.), The biology of the guinea pig (pp. 31-51). New York: Academic Press.

Hofer, M. A. (1976). Olfactory denervation: Its biological and behavioral effects in infant rats. Joumal of Comparative and Physiological Psychology, 90, 829-838.

Hofer, M. A., Fisher, A., Shalr, H. (1981). Effects of infraorbital nerve section on survival, growth, and suckling behaviors of developing rats. Joumal of Comparative \& Physiological Psychology, 95, 123-133.

Hofer, M. A., Shair, H., \&ingh, P. (1976). Evidence that maternal ventral skin substances promote suckling in infant rats. Physiology \& Behavior, 17, 131-136.

KEIPER, R. R. (1985). The Assateague ponies. Centreville, MD: Tidewater.

Kenyon, C. A. P., Cronin, P., Keeble, S. (1983). Role of the infraorbital nerve in retrieving by perioral anesthesia. Behavioral Neuroscience, 97, 255-269.

Kow, L.-M., Montgomery, M. O., Pfaff, D. W. (1977). Effects of spinal cord transections on lordosis reflex in female rats. Brain Research, 123, 75-88.

Mayer, A. D., Carter, L., Jorge, W. A., Moto, M. J., Tannu, S., - Rosenblatt, J. S. (1987). Mammary stimulation and aggression in rodents: Thelectomy fails to reduce pre- or postpartum aggression in rats. Hormones \& Behavior, 21, 501-510.

MolTZ, H., Geller, D., \& LeVIN, R. (1967). Maternal behavior in the totally mammectomized rat. Joumal of Comparative and Physiological Psychology, 64, 225-229.

PFaff, D., Modianos, D. (1985). Neural mechanisms of female reproductive behavior. In N. Adler, D. Pfaff, \& R. W. Goy (Eds.), Handbook of behavioral neurobiology: Vol. 7. Reproduction (pp. 423493). New York: Plenum Press.

RosenblatT, J. S. (1967). Nonhormonal basis of maternal behavior in the rat. Science, 156, 1512-1514.

Singh, P. J., \& TовАCH, E. (1975). Olfactory bulbectomy and nursing behavior in rat pups. Developmental Psychobiology, 8, 151-164.

Slujper, E. J. (1979). Whales. New York: Comell University Press.

STERN, J. M. (1977). Effects of ergocryptine on postpartum maternal behavior, ovarian cyclicity and food intake in rats. Behavioral Biology, 21, 134-140.
STERN, J. M. (1989). Maternal behavior: Sensory, hormonal, and neural determinants. In F. R. Brush \& S. Levine (Eds.). Psychoendocrinology (pp. 105-226). New York: Academic Press.

STERN, J. M. (1990). Multisensory regulation of maternal behavior and masculine sexual behavior: A revised view. Neuroscience \& Biobehavioral Reviews, 14, 183-200.

STERN, J. M. (1991). Nursing posture is elicited rapidly in maternallynaive, haloperidol-treated, female and male rats in response to ventral trunk stimulation from active pups. Hormones \& Behavior, 25 , 504-517.

Stern, J. M., Dix, L., Pointek, C., \& Thramann, C. T. (1990). Ventral somatosensory determinants of nursing behavior in rats: Effects of nipple loss or anesthesia. Society for Neuroscience Abstracts, 15, 600.

STERN, J. M., \& Johnson, S. K. (1989). Perioral somatosensory determinants of nursing behavior in Norway rats. Joumal of Comparative Psychology, 103, 269-280.

STERN, J. M., JoHNSON, S. K. (1990). Ventral somatosensory determinants of nursing behavior in Norway rats: $I$. Effects of variations in the quality and quantity of pup stimuli. Physiology \& Behavior, 47, 993-1011.

Stern, J. M., KolUnie, J. M. (1989). Perioral anesthesia disrupts maternal behavior during early lactation in Long-Evans rats. Behavioral \& Neural Biology, 52, 20-38.

Stern, J. M., \& Levine, S. (1972). Pituitary-adrenal activity in the postpartum rat in the absence of suckling stimulation. Hormones \& Behavior, 3, 237-246.

Stern, J. M., Mackinnon, D. A. (1976). Postpartum, hormonal, and nonhormonal induction of maternal behavior in rats: Effects on T-maze retrieval of pups. Hormones \& Behavior, 7, 305-316.

STERN, J. M., \& TAYLOR, L. A. (1989). Dopaminergic effects on maternal behavior and milk ejection in lactating rats. Society for Neuroscience Abstracts, 15, 1158 .

StERn, J. M., TAYLOR, L. A. (1991). Haloperidol inhibits maternal retrieval and licking, but enhances nursing behavior and litter weight gains in lactating rats. Journal of Neuroendocrinology, 3, 591-596

VINCE, M. A. (1987). Tactile communication between ewe and lamb in the onset of suckling. Behaviour, 101, 156-176.

WIEsNer, B. P., SheARD, N. M. (1933). Maternal behaviour in the rat. London: Oliver \& Boyd.

(Manuscript received August 12, 1991; revision accepted for publication December 10, 1991.) 